\title{
Dopaminergic Modulation of Cortical Inputs during Maturation of Adult-Born Dentate Granule Cells
}

\author{
Yangling Mu, Chunmei Zhao, and Fred H. Gage \\ Laboratory of Genetics, The Salk Institute for Biological Studies, La Jolla, California 92037
}

Adult neurogenesis, a particular form of plasticity in the adult brain, is under dynamic control of neuronal activity mediated by various neurotransmitters. Despite accumulating evidence suggesting that the neurotransmitter dopamine (DA) regulates proliferation of neural precursor cells in the neurogenic zones, whether and how it acts on newly generated neurons that integrate into the established network remains unknown. Using patch-clamp recordings from retrovirus-labeled newborn hippocampal dentate granule cells (DGCs) in acute mouse brain slices, we found that DA not only caused a long-lasting attenuation of medial perforant path (MPP) inputs to the young DGCs, but also decreased their capacity to express long-term potentiation (LTP). In contrast, DA suppressed MPP transmission to mature DGCs to a similar extent but did not influence their LTP expression. This difference was linked to activation of distinct subtypes of DA receptors in DGCs at different developmental stages. Our observations suggest that DA is particularly effective in modulating the activities of hyperexcitable young neurons, which may have important implications for the dentate function as a filter for incoming information to the hippocampus.

\section{Introduction}

New neurons are continuously generated in the dentate gyrus (DG) throughout the adult life of a variety of mammals (Altman and Das, 1965; Eriksson et al., 1998). Their maturation and integration into the existing circuitry follow a precise sequence that resembles neonatal hippocampal development (Espósito et al., 2005). It usually takes $\sim 4$ weeks for newborn neurons to achieve mature connectivity (Espósito et al., 2005), and $\sim 8$ weeks to display mature morphology (Zhao et al., 2006). Developing neurons ( $\leq 6$ weeks after birth) in adult DG exhibit physiological properties that are different from mature dentate granule cells (DGCs), including enhanced excitability, decreased induction threshold, and increased amplitude for long-term potentiation (LTP) (Wang et al., 2000; Snyder et al., 2001; Schmidt-Hieber et al., 2004; Ge et al., 2007). Although the exact contribution of newly born DGCs to hippocampal physiology and behavior remains to be clarified, increasing lines of evidence have suggested that they are involved in learning and memory as young as $\sim 2-4$ weeks of age (Shors et al., 2001; Bruel-Jungerman et al., 2005; Snyder et al., 2005). Nevertheless, existing studies on the functional properties of new neurons have been limited to their integration into the entorhinal cortex-hippocampal loop circuits. Almost nothing is known about how new neurons integrate into the broader hippocampal circuitry, which includes modulatory inputs to the DG from various subcortical structures.

\footnotetext{
Received Sept. 18, 2010; revised Jan. 12, 2011; accepted Jan. 17, 2011.

This work was supported by grants from James S. McDonnell Foundation, Kavli Institute for Brain and Mind, the Lookout Fund, and National Institute of Mental Health Grant MH090258. We thank Nicole Coufal for help with the qPCR experiment; James B. Aimone and Alejandro F. Schinder for helpful discussions and comments on the manuscript; Mary Lynn Gage for editorial comments; and Jamie Simon for assistance with figures.

Correspondence should be addressed to Fred H. Gage at the above address. E-mail: gage@salk.edu.

DOI:10.1523/JNEUROSCI.4913-10.2011

Copyright $\odot 2011$ the authors $\quad 0270-6474 / 11 / 314113-11 \$ 15.00 / 0$
}

The hippocampal formation is innervated by dopaminergic projections originating from the ventral tegmental area (VTA), the adjacent substantia nigra, and the retrorubral fields (Gasbarri et al., 1997). Dopaminergic neurites contact progenitor cells in the subgranular zone (SGZ) of DG (Höglinger et al., 2004) and form symmetric synapses with dendrites and perikarya of DGCs (Milner and Bacon, 1989). It has been proposed that dopamine (DA) controls the proliferation of neural precursor cells (NPCs) in the SGZ, although conflicting results have been reported (Höglinger et al., 2004; Domínguez-Escribá et al., 2006; Park and Enikolopov, 2010). Correspondingly, the number of NPCs is reduced in neurogenic regions of individuals with Parkinson's disease, a disorder characterized by DA depletion resulting from degeneration of dopaminergic neurons (Höglinger et al., 2004). Despite emerging studies revealing the role of DA in the early phases of adult neurogenesis, dopaminergic regulation of functional integration of nascent neurons has yet to be determined. This lack of available data prompted us to investigate whether and how DA regulates information processing by DGCs; specifically, whether DA influences newborn DGCs differently than their older counterparts.

By labeling and birthdating newly generated DGCs in adult mice, we used whole-cell patch-clamp approaches to examine the impact of DA on entorhinal excitatory input to DGCs at discrete developmental stages. We observed a critical period when both the efficacy and LTP of medial perforant path (MPP) transmission to adult-born DGCs were downregulated by activation of $\mathrm{D}_{1}$-like receptors. Although DA had a general inhibitory effect on synaptic transmission to mature DGCs as well, it exerted its action via $\mathrm{D}_{2}$-like receptors and did not influence LTP in mature cells. Together, our results suggest that the responses of adult-born neurons to DA vary with developmental periods, and this differential regulation by neuromodulators poten- 
tially affects the contributions of young neurons to the function of the entire DG.

\section{Materials and Methods}

Retrovirus injection. Human embryonic kidney 293T (HEK293T) cells were transfected with murine Moloney leukemia virus-based retroviral vector encoding green fluorescent protein (GFP), and the viruses were harvested from infected cultures as previously described (Zhao et al., 2006). The concentrated viral solution $\left(10^{7}-10^{8}\right.$ colony-forming units/ $\mathrm{ml}$ ) was delivered to the DG of the mouse hippocampus through stereotaxic surgery to label dividing NPCs and their progeny. The injection site was determined using spatial coordinates relative to bregma, where $d$ represents the distance between bregma and lambda, as follows: anteroposterior $=-d / 2 \mathrm{~mm}$; lateral $=-1.6($ if $d \leq 1.6 \mathrm{~mm})$ or $-1.7 \mathrm{~mm}$; and ventral $=-1.9 \mathrm{~mm}$ (from dura). The mice used for injection were female C57BL/ 6 and were $6-7$ weeks old at the time of surgery. They were then housed in standard cages before any further experimentation. All experimental procedures were approved by the Salk Institutional Animal Care and Use Committee.

Immunohistochemistry and microscopy. The retrovirus-infected mice were anesthetized with a mixture of ketamine/xylazine $(100 \mathrm{mg} / \mathrm{kg}$ and $10 \mathrm{mg} / \mathrm{kg}$, respectively) and perfused transcardially with $0.9 \%$ saline followed by $4 \%$ paraformaldehyde. After decapitation, the mouse brains were fixed with $4 \%$ paraformaldehyde and equilibrated in 30\% sucrose. Coronal slices of $40 \mu \mathrm{m}$ thickness were cut with a sliding microtome. A polyclonal anti-mouse tyrosine hydroxylase (TH) antibody (1:250 dilution; Protos Biotech) and a monoclonal anti-mouse NeuN antibody (1: 10) were used for immunostaining. A biotin-conjugated secondary antibody (1:250 dilution; Jackson ImmunoResearch) and a Cy5-coupled secondary antibody (1:250 dilution; Jackson ImmunoResearch) were used against the primary anti-TH and anti-NeuN antibodies, respectively. Biotin-labeled antibodies were then detected using streptavidin coupled to Cy3 (1:250 dilution; Jackson ImmunoResearch). Immunostained tissue samples were mounted on glass slides, and fluorescence images were obtained using a Zeiss LSM 710 laser scanning confocal microscope. Image stacks were collected with a $20 \times$ objective lens at a digital zoom of 4 and were compressed into a single plane by using a maximum intensity projection and ZEN software.

Quantitative real-time PCR of DA receptor mRNA. Female C57BL/6 mice (10 weeks old) housed under standard conditions were used in this study. The DG, CA1, and CA3 of the hippocampus and striatum were microdissected from the fresh mouse brains as described before (Zhao et al., 2001) and frozen separately at $-80^{\circ} \mathrm{C}$ in RNA-Bee reagent (Tel-Test) immediately. Tissues from five mice were pooled in one group to increase the quantity of RNA and to minimize animal-to-animal variation. For better quantification, three groups of animals were dissected and processed independently using identical procedures. For extraction of total RNA, the tissues were homogenized in RNA-Bee reagent, and the homogenate was separated into aqueous and organic phases as described by the manufacturer. The pure RNA was obtained from the aqueous phase by isopropanol precipitation, and the pellet was dissolved in $10 \mu \mathrm{l}$ of DEPC (diethylpyrocarbonate)-treated sterile distilled water. Quantitation of RNA obtained from these samples was performed with a NanoDrop ND-1000 Spectrophotometer. For each quantitative PCR (qPCR) reaction, $2 \mu \mathrm{g}$ of total RNA was used, and the mRNA was first reverse transcribed into cDNA using SuperScript III reverse transcriptase (RT) (Invitrogen). Aliquots of cDNA and primers were then added to SYBR Green Master Mix (Applied Biosystems). PCR amplifications were run on 96-well optical reaction plates using an ABI Prism 7000 sequence detection system, and data analysis was performed with SDS 2.3 software (Applied Biosystems). Each condition was acquired in triplicate. Primer pairs for all five subtypes of DA receptors were designed using Primer Express Software (Applied Biosystems). Total RNA extracted from mouse whole brain was used to generate a standard curve by qPCR for every gene, and the efficiency of each primer pair was verified by linear regression to the standard curve. Serial dilutions of total RNA from whole brain were used as standards to quantify mRNA levels of the housekeeping gene glyceraldehyde 3-phosphate dehydrogenase (GAPDH). The amount of each subtype of DA receptor mRNA was
Table 1. Sequences of the primers used for qPCR analysis

\begin{tabular}{lll}
\hline Gene & Sense & Anti-sense \\
\hline D1R & GAGCAGGACATACGCCATTT & AGtTCTTGGCATGGACTGCT \\
D2R & GCACAGCAAGCATCTTGAC & AGGACAGGACCCAGACAATG \\
D3R & AGGCAAAGGGAAGAAAAC & GTGGCATCTGACAGAAACC \\
D4R & TTCAACCTGTGCGCCATCAG & TCATTGAGGCCACACACCAC \\
D5R & CCGTATCTCCTCCCTAGAAAGG & ACGAAGACCCCCATGATCAC \\
GAPDH & ACCCAGAAGACTGTGGATG & CACATTGGGGTAGGAACAC \\
\hline
\end{tabular}

$D 1 R, D_{1}$ receptor; $D 2 R, D_{2}$ receptor; $D 3 R, D_{3}$ receptor; $D 4 R, D_{4}$ receptor; $D 5 R, D_{5}$ receptor.

calculated according to the standard curve for its particular primer set. The relative expression level of each receptor was then normalized to that of GAPDH mRNA. Sequences of the primers used for qPCR are listed in the order of $5^{\prime} \rightarrow 3^{\prime}$ in Table 1 .

Electrophysiology. The mice injected with retrovirus expressing GFP were anesthetized by isoflurane inhalation after being housed in standard cages for different periods of time. The brains were immediately removed and placed in ice-cold artificial CSF (ACSF) containing the following (in $\mathrm{mm}$ ): choline chloride $110, \mathrm{KCl} 2.5, \mathrm{NaH}_{2} \mathrm{PO}_{4} 1.3, \mathrm{NaHCO}_{3} 25.0, \mathrm{CaCl}_{2}$ $0.5, \mathrm{MgCl}_{2} 7$, glucose 20, Na-ascorbate 1.3 , and Na-pyruvate 0.6 . Horizontal slices (200 $\mu \mathrm{m}$ thick) were cut using a Leica VT1000S vibrotome and incubated in standard ACSF composed of the following (in $\mathrm{mM}$ ): $\mathrm{NaCl} 125, \mathrm{KCl} 2.5, \mathrm{NaH}_{2} \mathrm{PO}_{4} 1.3, \mathrm{NaHCO}_{3} 25, \mathrm{CaCl}_{2} 2, \mathrm{MgCl}_{2}$ 1.3, $\mathrm{Na}$-ascorbate 1.3 , Na-pyruvate 0.6 , and glucose 10 , saturated with $95 \%$ $\mathrm{O}_{2}$ and $5 \% \mathrm{CO}_{2}$. After recovery at room temperature for at least $1 \mathrm{~h}$, the slices were transferred to the recording chamber. Whole-cell perforated patch recordings were obtained from DGCs visualized using an upright microscope (BX51WI; Olympus) with infrared differential interference contrast optics. The newborn cells were visually identified by their green fluorescence as well. During each recording, the slice was constantly perfused with fresh ACSF containing 50-100 $\mu \mathrm{m}$ picrotoxin to block GABAergic synaptic transmission, and all experiments were performed at room temperature. The micropipettes were made from borosilicate glass capillaries (Garner), with a resistance in the range of 3-6 M $\Omega$. The pipette was tip filled with internal solution composed of the following (in mM): K-gluconate 128, $\mathrm{KCl} 17.5, \mathrm{NaCl} 9, \mathrm{MgCl}_{2}$ 1, EGTA 0.2, and HEPES 10, $\mathrm{pH} 7.3$; then back-filled with the same internal solution containing amphotericin B $(200 \mu \mathrm{g} / \mathrm{ml})$. A bipolar tungsten electrode was used for extracellular stimulation of MPP, and DGCs were generally held at a constant potential of $-70 \mathrm{mV}$ in voltage-clamp mode unless stated otherwise. Data were acquired using patch-clamp amplifiers (Axopatch 200B; Molecular Devices). Signals were filtered at $2 \mathrm{kHz}$ and sampled at 5 $\mathrm{kHz}$ using a Digidata 1322A analog-digital interface (Molecular Devices). Input resistance and series resistance were monitored continuously during recordings. Series resistance was typically $\sim 20 \mathrm{M} \Omega$. The mean input resistance was $\sim 745 \mathrm{M} \Omega$ for newborn and $\sim 540 \mathrm{M} \Omega$ for mature DGCs. Data were accepted for analysis only if both series and input resistances remained relatively constant ( $<20 \%$ change) throughout the experiment. LTP was induced with four episodes of theta-burst stimulation (TBS) applied at $0.1 \mathrm{~Hz}$. Each episode of TBS consisted of trains of stimuli delivered every $200 \mathrm{~ms}$, with five pulses (at $100 \mathrm{~Hz}$ ) in each train. The extent of LTP was quantified by averaging the amplitude of EPSCs during the last $10 \mathrm{~min}$ of experiments and normalizing the result to the mean baseline value. The paired-pulse ratio (PPR) was calculated as the ratio of the amplitude of the second EPSC to that of the first EPSC evoked by paired-pulse stimulation of MPP, and the coefficient of variation $(\mathrm{CV})$ was calculated as $\sigma / \mathrm{M}$, where $\sigma$ and $\mathrm{M}$ are the SD and the mean amplitude of first EPSC, respectively. Unless indicated, data were compared with either Student's $t$ test (paired or unpaired) or Wilcoxon signed-rank test, and results associated with $p<0.05$ were considered to be statistically significant. All the agonists and antagonists for DA receptors were purchased from Tocris Bioscience and added to the external solution as indicated. The other drugs were obtained from Sigma.

$D G C$-specific RT-PCR. Entire DGCs were harvested from acute mouse brain slices using patch-clamp capillaries (baked $4 \mathrm{~h}$ at $225^{\circ} \mathrm{C}$ ) filled with RNase-free intracellular buffer (composition described above in Electrophysiology). A total of six to seven cells was collected in one pipette to increase the quantity of RNA, and the pipette contents were then expelled 

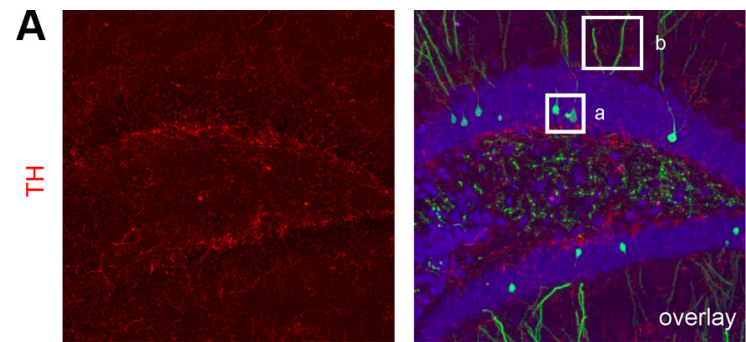

B
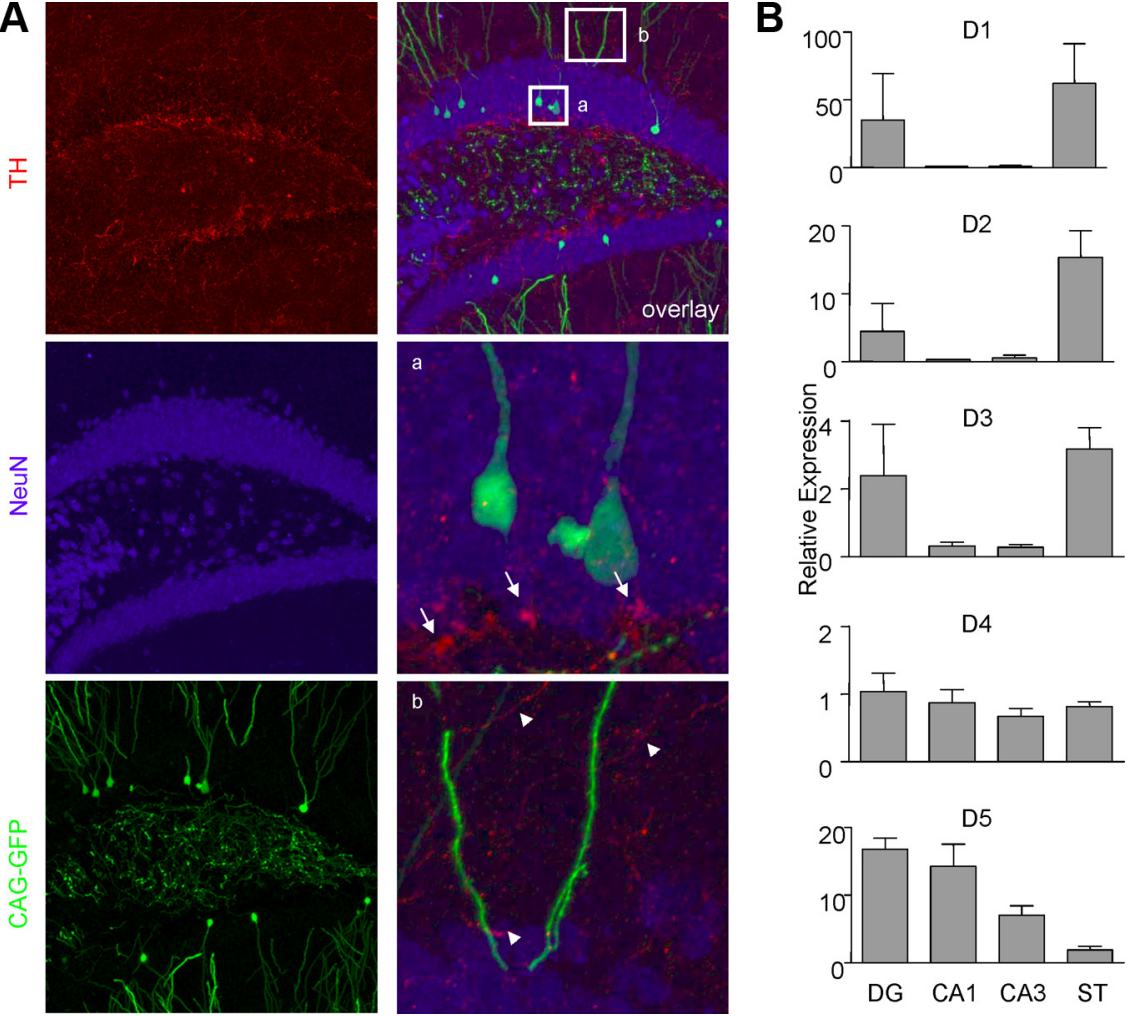

Figure 1. Dopaminergic innervation and receptors in the DG. $\boldsymbol{A}$, Left column, Immunostaining of TH (red), NeuN (blue), and $\mathrm{GFP}^{+}$newborn DGCs (green) in the DG. Right column, Merged images of left panels (top) and enlargement of boxed regions a (middle) and b (bottom). Arrows, $\mathrm{TH}^{+}$puncta in the SGZ. Arrowheads, $\mathrm{TH}^{+}$fibers in the molecular layer. $\boldsymbol{B}$, Expression profile of $D A$ receptor subtypes in DG, CA1, CA3, and striatum as determined by qPCR. The relative amount of mRNA for each subtype of DA receptor was normalized to that for $\mathrm{GAPDH}$, and each bar represents the average of values obtained from triplicates. Error bars indicate \pm SEM.

into a sterile $0.5 \mathrm{ml}$ PCR tube (Bio-Rad). The RNA was converted to cDNA through reverse transcription (SuperscriptIII; Invitrogen). About one quarter of the final RT sample was subsequently analyzed by two rounds of PCR amplification (GoTaq flexi; Promega) using specific primers for $D_{1}, D_{2}$, and $D_{5}$ receptors and housekeeping gene GAPDH (sequences the same as those used for qPCR). Therefore, cDNAs of only 1.5-1.75 cells were used for each PCR. GAPDH could be detected reliably from essentially all samples tested.

\section{Results}

Differential regulation of newborn and mature DGCs by DA

The major terminal fields of dopaminergic projections to the hippocampal formation are located in the ventral/dorsal subiculum and CA1 (Gasbarri et al., 1997). Few afferents from mesohippocampal dopaminergic neurons are observed in the DG (Leranth and Hajszan, 2007). To verify the presence of dopaminergic afferents to adult-born DGCs, we injected 6- to 7-weekold mice with retrovirus carrying GFP transgene by stereotaxic surgery to label and birthdate newly generated granule cells. The mice were killed at different time points after retroviral injection. The brain sections were immunostained for $\mathrm{TH}$, the rate-limiting enzyme in DA synthesis, and immunoreactivity for pan-neuronal marker NeuN was included to visualize the granule cell layer. As shown in Figure $1 \mathrm{~A}, \mathrm{TH}^{+}$dopaminergic fibers were largely found in a diffuse and sparse pattern, and the staining intensity varied from weak to moderate throughout the dentate area. Small immunopositive puncta of relatively higher intensity were readily found in the SGZ, where the NPCs are located. At a higher magnification, $\mathrm{TH}^{+}$dopaminergic fibers were found to be in the vicinity of both dendrites and somata of newborn DGCs. These results suggest that the processing of cortical inputs to the principal neurons of DG may be influenced by DA.

DA exerts its action via $D_{1}$-like $\left(D_{1}\right.$ and $\left.\mathrm{D}_{5}\right)$ and $\mathrm{D}_{2}$-like $\left(\mathrm{D}_{2}, \mathrm{D}_{3}\right.$, and $\left.\mathrm{D}_{4}\right)$ families of receptors. Typically, these two classes of receptors lead to opposite changes in intracellular cAMP levels and trigger distinct signaling cascades that culminate in gene transcription (Missale et al., 1998). To evaluate the expression levels of DA receptors in the DG, we performed qPCR analysis of RNA extracted from microdissected adult mouse brain regions (DG, CA1, CA3, and striatum). The DA receptor measurement for each brain subregion was normalized over a simultaneously performed qPCR of the housekeeping gene GAPDH in that area. Each DA receptor subtype showed a trend of consistent expression in the DG (compared with 0 , $p=0.1$, Wilcoxon signed-rank test), and their expression levels were comparable to those in the striatum (Fig. 1B), a brain area that has been demonstrated to express all five DA receptor mRNAs (Missale et al., 1998). Furthermore, $D_{1}, D_{2}$, and $\mathrm{D}_{5}$ receptors had higher expression levels than the other subtypes in the DG. In contrast, the $\mathrm{D}_{5}$ receptor appeared to be the only subtype that showed marked expression in CA1 and CA3. Overall, DA receptors exhibited higher expression in the DG than in the other hippocampal subregions, indicating a particular role for DA in DG function.

To investigate the physiological effects of DA, we applied DA to acute horizontal brain slices from retrovirus-infected animals and examined its actions on excitatory cortical inputs to DGCs. Neurons generated during adulthood $\left(\mathrm{GFP}^{+}\right)$at $4-6$ weeks postinfection (wpi) and those generated during early development $\left(\mathrm{GFP}^{-}\right)$were recorded by visualized perforated whole-cell patch-clamp methods when stimulating electrodes were placed in the middle third of the molecular layer. EPSCs evoked by this method mainly represented MPP-elicited responses, as evidenced by their different sensitivity to mGluR (metabotropic glutamate receptor) agonist $\mathrm{AP} 4$ and $\mathrm{GABA}_{\mathrm{B}}$ agonist baclofen (supplemental Fig. S1, available at www.jneurosci.org as supplemental material). After a 10 min stable baseline of evoked EPSCs was achieved, DA $(10-20 \mu \mathrm{M})$ was applied through bath perfusion for $5 \mathrm{~min}$, which decreased the EPSC amplitude by $26.2 \pm 6.5 \%$ and $30.9 \pm 4.6 \%$, respectively, in $\mathrm{GFP}^{+}(n=8)$ and GFP ${ }^{-}(n=15)$ DGCs (at 30-40 min). In contrast, there was no significant reduction in EPSCs in time-matched saline controls $\left(\mathrm{GFP}^{+}: 1.8 \pm 6.8 \%, n=4 ; \mathrm{GFP}^{-}: 4.5 \pm 5.5 \%, n=5\right)$ (Fig. 2A). DA-induced inhibition developed slowly and was long lasting. It persisted as long as the recording remained stable (up to $95 \mathrm{~min}$ after washout of DA), indicating that DA induced a novel form of long-term depression (LTD) in the DG.

To ascertain the ability of endogenous DA to modulate MPP inputs to DGCs, we next investigated the action of amphetamine 
(AMT), a psychostimulant that is known to actively promote DA release. As shown in Figure $2 B$, AMT $(30 \mu \mathrm{M})$ decreased the amplitude of EPSCs in GFP ${ }^{-}$neurons by $22.8 \pm 4.1 \%(n=6)$. Interestingly, the same drug treatment did not cause any significant effect on EPSCs in 4 wpi GFP ${ }^{+}$ neurons, but administration of AMT at a much higher concentration $(60 \mu \mathrm{M})$ reduced their EPSC amplitudes by $35.9 \pm$ $4.9 \%(n=5)$. Preincubation of the brain slices in $\mathrm{D}_{1}$-like receptor antagonist $\mathrm{SCH}$ $23390(10 \mu \mathrm{M})$, but not $\mathrm{D}_{2}$-like receptor antagonist sulpiride $(10 \mu \mathrm{M})$, for at least 30 min before infusion of AMT largely abolished the synaptic changes in $\mathrm{GFP}^{+}$ cells. In contrast, the same pretreatment with sulpiride, but not SCH 23390, prevented the depressive effect of AMT on $\mathrm{GFP}^{-}$neurons (Fig. $2 \mathrm{~B}$ ). These results suggest that endogenous DA releasable by AMT suppressed MPP inputs to both adult- and neonate-born DGCs through $\mathrm{D}_{2}$ - and $\mathrm{D}_{1}$-like receptor subtypes, respectively. Furthermore, the need for a higher concentration of AMT in newborn neurons might be attributed to a lower AMTinduced synaptic DA level resulting from fewer dopaminergic synapses on young cells and/or lower efficacy of the corresponding synapses.

DA is an important modulator of LTP at glutamatergic synapses throughout the brain (Jay, 2003; Lisman and Grace, 2005). Most studies in the hippocampus have focused on its role in the CA1 area and during tetanization, which produces LTP. Here we sought to understand whether DA could leave a trace in the learning ability after its removal (i.e., whether it could induce lasting changes that regulate how synapses respond to subsequent induction of LTP). To address this issue, we compared the magnitudes of LTP induced before and after exposure to DA. In naive control slices, evoked EPSCs could be reliably potentiated by TBS in both $\mathrm{GFP}^{+}(n=$ $11)$ and $\mathrm{GFP}^{-}(n=16)$ neurons. Consistent with previous findings (Snyder et al., 2001; Ge et al., 2007), the average enhancement level of EPSCs in GFP ${ }^{+}$DGCs was significantly higher than that in mature $\mathrm{GFP}^{-}$cells. In contrast, when the TBS protocol was applied $50 \mathrm{~min}$ after DA application, the mean magnitude of LTP in GFP ${ }^{-}$DGCs $(n=6)$ was not changed, whereas that in $\mathrm{GFP}^{+} \operatorname{DGCs}(n=5)$ was dramatically decreased (Fig. $2 C$ ). Thus, DA exclusively reduced the capacity of MPP synapses on immature adult-generated DGCs to undergo plastic changes. This finding suggests that the DG may encode information differently before and after events that stimulate DA release. Induction of LTP by high-frequency stimulation is predominantly mediated by activation of NMDA receptors (Nicoll and Malenka, 1999). We thus speculated that DA modulated synaptic plasticity of newborn neurons by modification of NMDA receptors, and we explored the possibility by recording isolated NMDA component in $\mathrm{Mg}^{2+}$-free ACSF $\left(4 \mathrm{mM} \mathrm{Ca}^{2+}\right.$ ) with 10 $\mu \mathrm{M}$ CNQX and $50 \mu \mathrm{M}$ picrotoxin. As shown in supplemental Fig. S2 (available at www.jneurosci.org as supplemental mate- rial), the amplitude of NMDA currents in 4 wpi GFP ${ }^{+}$DGCs was decreased by $21.1 \pm 3.3 \%$ at $30-40$ min after perfusion of DA $(n=4)$. Therefore, DA attenuated LTP expression in young neurons, probably by inhibiting synaptic NMDA receptor responses.

\section{$\mathrm{D}_{2}$-like receptor-mediated attenuation of cortical inputs to mature DGCs}

To pharmacologically characterize the subtype of receptors involved in differential modulation of entorhinal excitation by DA, we examined the actions of selective agonists of $D_{1}$ and $D_{2}$ receptor families on evoked EPSCs, respectively. The first set of recordings was performed from $\mathrm{GFP}^{-}$DGCs residing in the outermost granule cell layer, which is predominantly occupied by neurons born during early development (Wang et al., 2000). EPSCs were evoked by low-frequency (once every 20 or $30 \mathrm{~s}$ ) paired-pulse stimulation (interpulse interval, $50 \mathrm{~ms}$ ) of MPP. After stable baseline measurements of EPSCs for at least $10 \mathrm{~min}$, DA receptor agonists were bath applied for $5 \mathrm{~min}$, followed by a washout period of $40 \mathrm{~min}$. As shown in Figure $3 A$, the amplitude of the first EPSC in response to paired-pulse stimulation remained unchanged after bath application of $10 \mu \mathrm{M} \mathrm{D} \mathrm{D}_{1}$-like receptor agonist SKF $38393(n=8)$. In contrast, treatment with $10 \mu \mathrm{M}$ quinpirole, a selective $\mathrm{D}_{2}$-like receptor agonist, decreased the EPSC amplitudes by $28.9 \pm 4.7 \%(n=12)$ (Fig. $3 B)$. These results suggest 

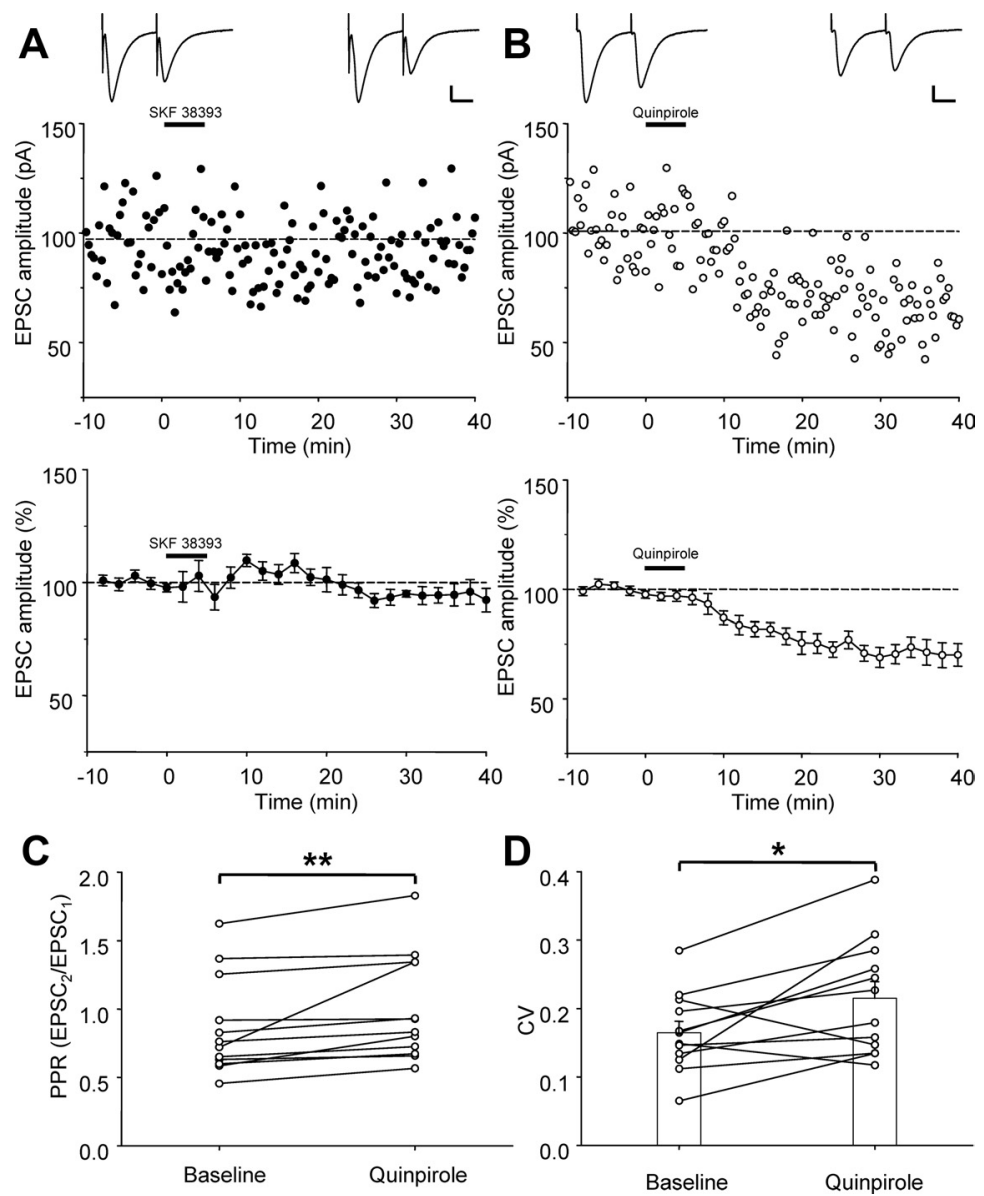

Figure 3. Activation of $D_{2}$-like receptors downregulates the strength of MPP synapses to neonate-generated DGCs.A, Top, Bath application of SKF $38393(10 \mu \mathrm{m}, 5 \mathrm{~min})$ as indicated by the black bar has no significant effect on the amplitude of evoked EPSCs in $\mathrm{GFP}^{-}$granule cells. Shown above are sample EPSCs (average of 30 consecutive traces; scales: 20 pA, $20 \mathrm{~ms}$ ). Bottom, Summary of all data obtained from GFP ${ }^{-}$cells treated with SKF $38393(n=8)$. Data represented in the same manner as in Figure 2A. $\boldsymbol{B}$, Top, The presence of $10 \mu \mathrm{m}$ quinpirole for $5 \mathrm{~min}$ (black bar) leads to a long-lasting decrease in the amplitude of evoked EPSCs in GFP granule cells. Sample EPSCs averaged from 30 consecutive trials before and after drug application are shown above (scales: $20 \mathrm{pA}$, $20 \mathrm{~ms})$. Bottom, Summary data showing the effect of quinpirole on EPSCs in GFP ${ }^{-}$DGCs in response to MPP stimulation $(n=12)$. Data are presented as in $A$. C, The depression of EPSCs induced by quinpirole is accompanied by an increase in the PPR. ${ }^{* *} p<0.001$, Wilcoxon signed-rank test. Each point represents the average of 30 consecutive trials before and after perfusion of quinpirole from one experiment. $\boldsymbol{D}$, The $C V$ is significantly changed after LTD induction by quinpirole. ${ }^{*} p<0.05$, Wilcoxon signed-rank test. Error bars show \pm SEM.

that activation of $\mathrm{D}_{2}$ - but not $\mathrm{D}_{1}$-like receptors was responsible for depressing excitatory cortical inputs to mature DGCs. Quinpirole produced a dose-dependent depression of evoked EPSCs. At a concentration of $1 \mu \mathrm{M}$, quinpirole decreased the EPSC amplitude to $85.6 \pm 1.2 \%$ of the baseline (at $10-20 \mathrm{~min}$ ) in a largely reversible manner $(n=4)$. The EPSC amplitude was reduced to $73.7 \pm 5.3 \%, 74.3 \pm 3.9 \%$, and $71.1 \pm 4.7 \%$ of the baseline, respectively, by $2 \mu \mathrm{M}(n=6), 5 \mu \mathrm{M}(n=4)$, and $10 \mu \mathrm{M}(n=12)$ quinpirole (supplemental Fig. S3A, available at www.jneurosci. org as supplemental material), suggesting that the maximally effective concentration of this $\mathrm{D}_{2}$ agonist was $\sim 2 \mu \mathrm{M}$. Furthermore, synaptic inhibition triggered by a $5 \mathrm{~min}$ infusion of $10 \mu \mathrm{M}$ quinpirole could not be reversed by subsequent application of $10 \mu \mathrm{M}$ sulpiride (supplemental Fig. S3B, available at www.jneurosci.org as supplemental material), indicating that transient activation of DA receptors indeed triggered a form of LTD.

The mechanism by which $\mathrm{D}_{2}$ agonist exerts its effect at MPPDGC synapses may involve a decrease in presynaptic glutamate release and/or a decrease in postsynaptic sensitivity to glutamate.
To clarify the locus of this depression, we compared the PPR and CV of EPSCs before and after drug application. These two measures are correlated with presynaptic release probability and therefore sensitive to manipulations altering it (Zucker and Regehr, 2002). The attenuation of evoked EPSCs resulting from quinpirole application was accompanied by a significant increase in both PPR (baseline: $0.87 \pm 0.10$; $30-40 \mathrm{~min}$ after quinpirole: $1.00 \pm 0.11$; $p<0.001$, Wilcoxon signed-rank test) (Fig. $3 C$ ) and CV (baseline: $0.16 \pm 0.02$; 30-40 min after quinpirole: $0.22 \pm 0.02$; $p<0.05$ ) (Fig. 3D). Thus, $\mathrm{D}_{2}$-like receptor-mediated suppression of evoked EPSCs appeared to act at least partially through inhibition of presynaptic release of glutamate, although the contributions of additional postsynaptic mechanisms could not be ruled out.

\section{$D_{1}$-like receptor-mediated attenuation of cortical inputs to immature DGCs}

We next used the same experimental design as described in Figure 3 to investigate receptors involved in DA regulation of MPP inputs to $\mathrm{GFP}^{+}$DGCs at 4-6 wpi, when most newborn cells have already integrated into the existing circuitry but have not yet fully matured morphologically or functionally (Espósito et al., 2005; Zhao et al., 2006). In contrast to the effect on MPP inputs to mature DGCs, bathapplied quinpirole did not cause any significant alteration in excitatory synaptic transmission at MPP-newborn DGC synapses, as shown by no changes in the amplitudes of the EPSCs in response to paired-pulse MPP stimulation after drug perfusion $(n=8)$ (Fig. $4 A$ ). Instead, the amplitude of the first EPSC was decreased to $71.7 \pm 5.6 \%(n=9)$ by bath application of SKF 38393, which was not associated with significant changes in PPR (baseline: $0.96 \pm 0.10$; after SKF 38393: $0.99 \pm 0.15$ ) or CV (baseline: $0.19 \pm 0.02$; after SKF 38393: $0.20 \pm 0.02$ ) (Fig. $4 B$ ). These results suggest that the attenuation of MPP inputs to newborn DGCs was mediated by $\mathrm{D}_{1}$-like receptors and seemed unlikely to involve a decrease in presynaptic release of glutamate. However, more direct evidence is needed to confirm its postsynaptic origin.

Applying the same experimental paradigm to $\mathrm{GFP}^{+}$DGCs at 8-11 wpi, we then examined whether adult-born DGCs maintained this property after they became morphologically and physiologically mature. Bath perfusion of quinpirole $(n=$ 14) instead of SKF $38393(n=8)$ resulted in $25.1 \pm 6.9 \%$ decrease of the first EPSC evoked by paired-pulse stimulation of MPP (Fig. 4C), and this synaptic depression was accompanied by an increase in both PPR (baseline: $0.77 \pm 0.06$; after quinpirole: $0.91 \pm 0.09 ; p<0.005$, Wilcoxon signed-rank test) and CV (baseline: $0.16 \pm 0.01$; after quinpirole: $0.21 \pm$ $0.02 ; p<0.001$ ) (Fig. 4D). Preincubation of the brain slices in SCH 23390 and sulpiride separately for at least $30 \mathrm{~min}$ before 
bath perfusion of the corresponding agonist completely prevented the changes in EPSC amplitude, confirming that the depressive effect of SKF 38393 and quinpirole was specifically mediated by $\mathrm{D}_{1}$ and $\mathrm{D}_{2}$-like receptors, respectively (Fig. $4 E$ ). It should be noted that application of either $\mathrm{D}_{1}$ or $\mathrm{D}_{2}$ antagonist on its own did not elicit significant alterations in basal synaptic transmission, suggesting that a tonic activation of $\mathrm{D}_{1}$ - or $\mathrm{D}_{2}$-like receptors did not contribute to basal synaptic transmission in DG. Together, our observations demonstrate that DA modulated synaptic responses of DGCs born during adulthood and during early development through activation of distinct subtypes of DA receptors, which then involved different synaptic mechanisms. Furthermore, the activated DA receptors shifted from a $D_{1}$ - to a $D_{2}$-like family during maturation of adult-born DGCs.

\section{Mechanisms underlying DA receptor-mediated depression}

The above results indicate that DA may induce a novel form of LTD via $\mathrm{D}_{1^{-}}$or $\mathrm{D}_{2}$-like receptor-dependent signaling in the DG. LTD in this region can also be induced both in vitro and in vivo by a variety of electrical stimulus protocols, the most common of which is low-frequency (1-2 Hz) stimulation (LFS) of MPP (Abraham, 1996). Accumulating evidence has shown that LFS-induced LTD-like processes contribute to hippocampal information storage, which is essential for learning and memory (Bear and Abraham, 1996; Kemp and ManahanVaughan, 2007). If DA-LTD and LFSLTD use a common mechanism for expression, generation of either one of them should occlude the other. To test this possibility, in the first experiment we delivered LFS (900 pulses at $1 \mathrm{~Hz}$ ) to MPP after minimal 10 min stable baseline recordings of evoked EPSCs in three groups of DGCs of different ages ( 4 wpi: $\mathrm{GFP}^{+} ; 4-5$ wpi, 8 wpi: $\mathrm{GFP}^{+}$; 8-9 wpi: mature, $\mathrm{GFP}^{-}$). The normalized EPSC amplitudes 20-30 min after LTD induction were $70.0 \pm 8.4 \%(4$ wpi: $n=5)$, $67.9 \pm 11.4 \%(8$ wpi: $n=4)$, and $68.7 \pm 3.7 \%$ (mature: $n=6$ ) of baseline (Fig. $5 A$ ). In the same brain slices, subsequent treatment with either $\mathrm{D}_{1}$ - or $\mathrm{D}_{2}$-like receptor agonist could not induce a further decline in the synaptic transmission (4 wpi: $103.5 \pm 1.7 \%$ of the baseline recorded in the last $10 \mathrm{~min}$ before drug perfusion; 8 wpi: $86.0 \pm 11.4 \%$; mature: $96.9 \pm 5.8 \%$ ). These results indicate that $\mathrm{D}_{1}$ - or $\mathrm{D}_{2}$-LTD was occluded by prior induction of LFSLTD. We next performed a reverse occlusion experiment in which LFS was delivered after DA receptor agonists were applied and the amplitude of EPSC had steadily declined to reach a plateau $(\sim 40-50$ min after drug application). Under this condition, LFS still induced LTD in all three groups of cells (Fig. 5A).

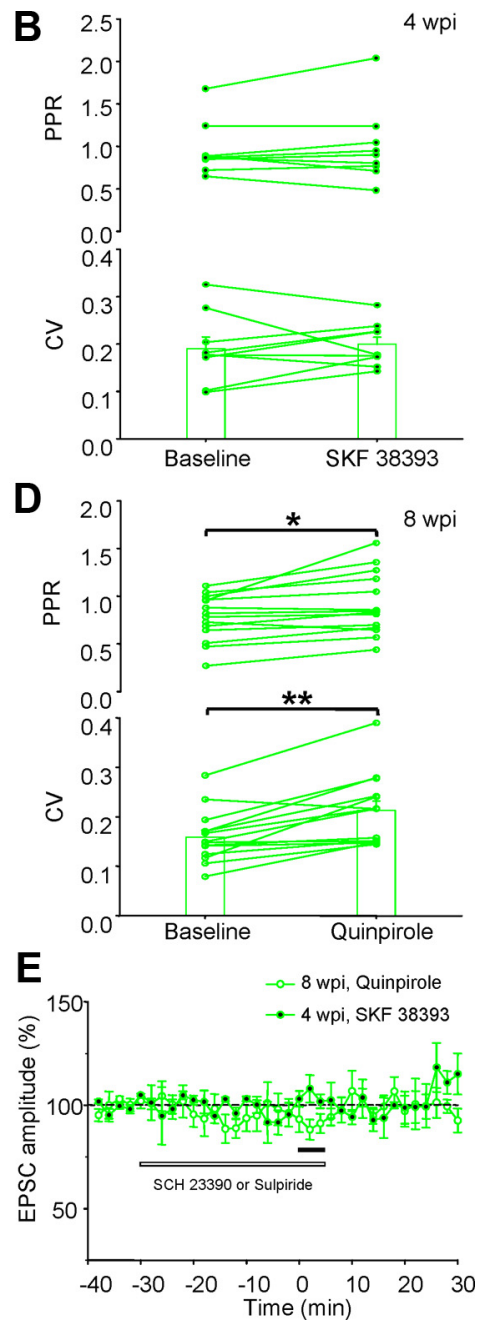

Figure 4. $\quad D_{1}$-like receptors contribute to inhibition of MPP synapses to adult-born DGCs (GFP ${ }^{+}$indicated by green) within a critical period. $\boldsymbol{A}$, Top, SKF 38393 perfusion (black bar) results in LTD of EPSCs evoked by MPP stimulation in a 4-week-old GFP data from GFP ${ }^{+}$DGCs at $4-6$ wpi treated with either SKF 38393 (filled circles; $n=9$ ) or quinpirole (open circles; $n=8$ ). Data are (bottom) is significantly changed after LTD induction in from experiments similar to those in $A$ except that all recorded GFP ${ }^{+}$DGCs are aged $8-11$ wpi. Bath perfusion of SKF 38393 (filled circles; $n=8$ ) has no significant effect on evoked EPSCS, whereas quinpirole (open circles; $n=14$ ) leads to a $25.1 \pm 6.9 \%$ (SEM) decrease of EPSC amplitude. D, Both PPR (top) and CV (bottom) exhibit significant increases after LTD induction in 8- to 11-weekold GFP ${ }^{+}$DGCs by $D_{2}$-like receptor activation. ${ }^{*} p<0.005,{ }^{* *} p<0.001$, Wilcoxon signed-rank test. $\boldsymbol{E}$, Pretreatment with $10 \mu \mathrm{M}$ SCH 23390 and sulpiride (white bar) prevents LTD induced by $D_{1}$ - and $D_{2}$-like agonists (black bar), respectively, in 4- to 6-week-old $\mathrm{GFP}^{+} \mathrm{DGCS}(n=3)$ and 8- to 11-week-old GFP ${ }^{+} \mathrm{DGCs}(n=4)$.

Compared with baselines recorded in the last 10 min before LFS, the normalized EPSC amplitudes 20-30 min after the end of LFS were $64.4 \pm 3.7 \%(4$ wpi: $n=6), 75.1 \pm 3.7 \%(8$ wpi: $n=4)$, and $79.4 \pm 5 \%$ (mature: $n=6$ ). The magnitudes of LFS-LTD after SKF 38393 or quinpirole treatment were not significantly different from those of LFS-LTD elicited in naive slices (Fig. 5B). In sum, induction of LFS-LTD fully blocked subsequent depression caused by $\mathrm{D}_{1}$ - or $\mathrm{D}_{2}$-like receptor agonists, but not vice versa, suggesting that the intracellular signaling mechanisms underlying DA receptor-mediated LTD do not fit exactly with LFS-LTD. One possibility is that LFS-LTD recruits both $\mathrm{D}_{1}$ - and $\mathrm{D}_{2}$ dependent components; therefore, LFS-LTD occludes either of them, whereas neither alone occludes LFS-LTD. Further investigation of whether LFS-LTD depends on $\mathrm{D}_{1}$ - and $\mathrm{D}_{2}$-like receptors could be undertaken to test this hypothesis. 

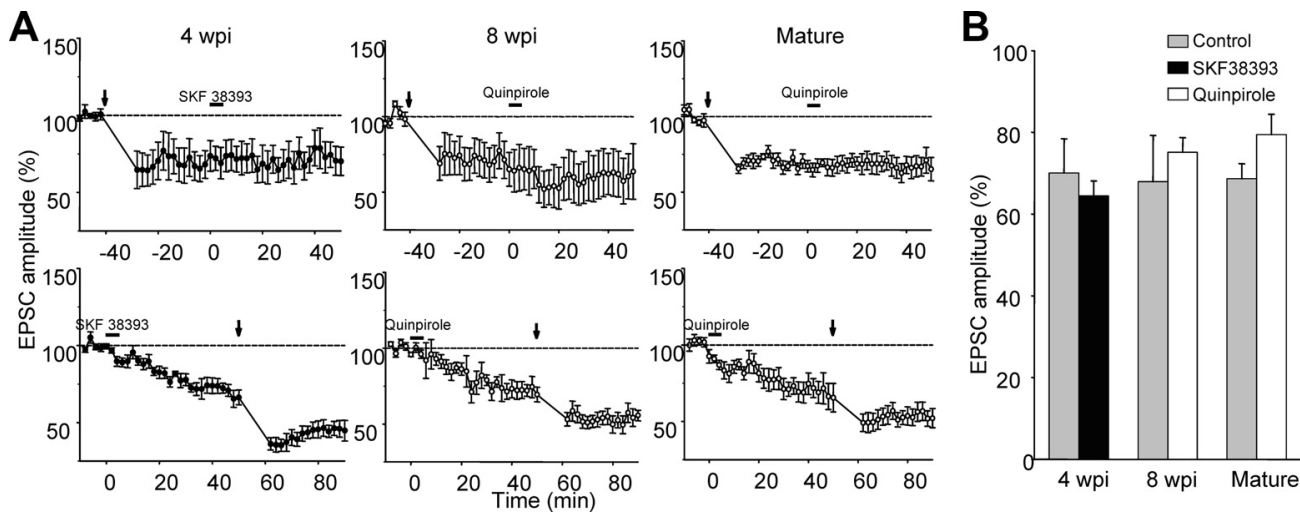

Figure 5. Relationship between DA agonist-induced LTD and LFS-LTD. A, Depression induced by $1 \mathrm{~Hz}$ LFS conditioning for $15 \mathrm{~min}$ (arrow) occludes pharmacologically induced LTD, but not vice versa. Top, LFS-LTD prevents subsequent induction of LTD by SKF 38393 (filled circles) or quinpirole (open circles) in 4-to 5-week-old newborn GFP ${ }^{+}$DGCs ( 4 wpi; $n=5$ ), 8-to 9-week-old GFP ${ }^{+}$DGCs (8 wpi; $\left.n=4\right)$, and GFP $^{-}$DGCs (Mature; $\left.n=6\right)$. Bottom, Expression of pharmacologically induced LTD does not occlude LFS-LTD in GFP ${ }^{+}$DGCsat 4 wpi $(n=6)$ and 8 wpi $(n=4)$, or in mature GFP ${ }^{-}$cells $(n=6)$.Values represent the mean of normalized EPSC amplitude (binned over 2 min spans) \pm SEM, and drug perfusion is indicated by the black bar. $B$, The magnitudes of LTD 20 - 30 min after the end of LFS in control drug-naive DGCS (gray) and in the cells perfused with SKF 38393 (black) or quinpirole (white) from experiments shown in $A$ are compared and summarized. Data represent mean \pm SEM.

A

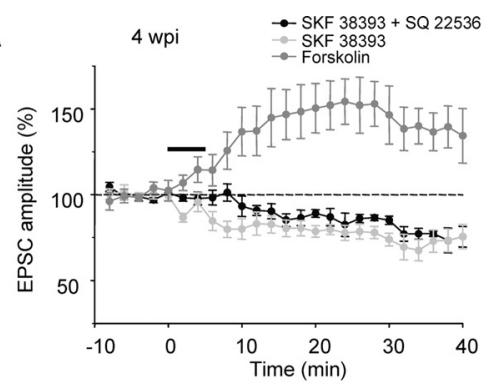

C

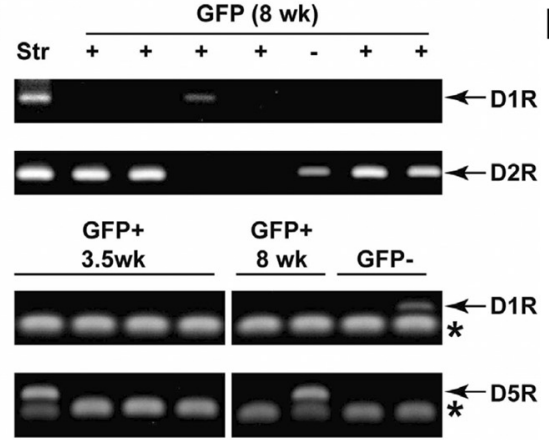

B

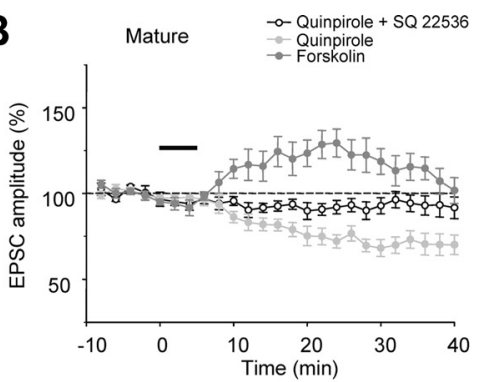

D

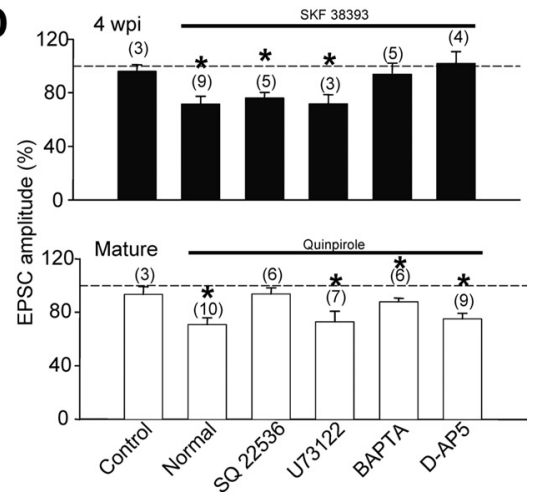

Figure 6. Mechanisms underlying DA receptor-mediated synaptic modulation. $A$, Summary (mean $\pm S E M$ ) of recordings from $\mathrm{GFP}^{+}$DGCs ( 4 wpi; $n=5$ ) treated with SKF 38393 in the presence of $100 \mu \mathrm{M}$ SQ 22536 (present throughout recordings) compared with those treated with forskolin $(10 \mu \mathrm{M})$. Black bar indicates application of SKF 38393 or forskolin. $\boldsymbol{B}$, Summary of experiments similar to that in $\boldsymbol{A}$ except from GFP ${ }^{-}$cells $(n=6)$ treated with quinpirole. Data presented in the same manner as in $\boldsymbol{A}$. C, DA receptors expressed in DGCs. The figure displays the typical result of multiple DGC-specific RT-PCR tests from indicated cell populations. Top, Both $D_{1}(D 1 R)$ and $D_{2}$ receptor $(D 2 R)$ genes demonstrate an amplification product in 8-week-old GFP ${ }^{+} D G C S$. D2R is detected in GFP ${ }^{-}$DGCs as well. Str represents positive control RNA from the striatum. Bottom, D1R detected in GFP ${ }^{-}$DGCs and D5R $\left(D_{5}\right.$ receptor) detected in GFP ${ }^{+}$cells ( 3.5 and 8 weeks old). Arrows indicate the PCR product of corresponding DA receptors. Asterisks (*) indicate primer bands. $\boldsymbol{D}$, Summary of all results from experiments similar to those in $\boldsymbol{A}$ and $\boldsymbol{B}$. The 4 wpi GFP ${ }^{+}$DGCs (top) and mature GFP ${ }^{-}$neurons (bottom) were treated with SKF 38393 and quinpirole, respectively, in the presence of $100 \mu \mathrm{m} \mathrm{SO}$ 22536, $10 \mu \mathrm{m}$ U73122, $10 \mu \mathrm{m}$ BAPTA-AM, or $25 \mu \mathrm{m}$ D-AP5 in the bath. Each bar represents the mean of normalized EPSC amplitude $30-40$ min after the end of baseline recording \pm SEM. ${ }^{*} p<0.05$, paired $t$ test. The total number of cells examined under each condition is indicated in parentheses.

$\mathrm{D}_{1^{-}}$and $\mathrm{D}_{2}$-like receptors are classically known to couple to G-proteins that regulate adenylyl cyclase (AC)-catalyzed cAMP formation, which then activates protein kinase A-dependent signaling cascades (Greengard, 2001). There is also evidence that both families may couple to phospholipase C (PLC)-mediated mobilization of intracellular $\mathrm{Ca}^{2+}$ (Neve et al., 2004). Down- stream, through diverse cAMP- or $\mathrm{Ca}^{2+}$ dependent mechanisms, DA influences synaptic transmission and plasticity by modulating the activity of various ion channels, receptors, and transcription factors. We first examined the participation of AC, whose activation regulates the production of cAMP. Since AC inhibitor SQ $22536(100 \mu \mathrm{M})$ inhibited baseline synaptic transmission on its own and the depression reached a plateau level within 40-50 min after drug infusion (supplemental Fig. S4A, available at www. jneurosci.org as supplemental material), the slices were preincubated with SQ 22536 for $>1$ h before new baseline recordings were acquired. The drug was then present in the superfusing medium throughout every recording. SKF 38393 added after AC inhibitor treatment still reduced the evoked EPSCs in 4-5 wpi $\mathrm{GFP}^{+}$neurons to $82.5 \pm 7.3 \%$ of the new baseline values. Although the progression of $D_{1}$ receptor-mediated suppression appeared to be slowed down by AC inhibition, the final magnitude of depression was comparable to that caused by SKF 38393 alone (Fig. 6A). In contrast, inhibition of AC by SQ 22536 largely abolished quinpirole-induced reduction of evoked EPSCs in $\mathrm{GFP}^{-}$neurons (Fig. $6 \mathrm{~B}$ ). These findings suggest that the AC/cAMP pathway contributed to $D_{2}$-LTD in mature DGCs but not $D_{1}$-LTD in young newborn cells. In diverse brain areas, $\mathrm{D}_{2}$ receptor activation has been shown to inhibit AC and subsequent cAMP formation (Missale et al., 1998). If this was the mechanism underlying $\mathrm{D}_{2}$-LTD, forskolin, a membrane-permeable direct activator of $\mathrm{AC}$, would be expected to raise cAMP levels and cause potentiation of EPSCs evoked by MPP stimulation. Indeed, bath application of forskolin $(10 \mu \mathrm{M})$ for $5 \mathrm{~min}$ produced a rapid and pronounced enhancement of the EPSC amplitude in neonate- 
Table 2. Summary of single-cell RT-PCR experiment

\begin{tabular}{lllll}
\hline & \multicolumn{2}{l}{$\mathrm{GFP}^{+}$} & & \\
\cline { 2 - 4 } & $3.5-4$ weeks & $>5$ weeks & $>8$ weeks & GFP $^{-}$ \\
\hline$D_{1}$ & & & $1 / 3$ & $1 / 11$ \\
$D_{2}$ & $0 / 16$ & $2 / 4$ & $4 / 9$ & $3 / 14$ \\
$D_{5}$ & $2 / 16$ & $1 / 4$ & $1 / 2$ & $1 / 11$ \\
\hline
\end{tabular}

Numerator indicates number of successful RT-PCR amplifications, and denominator indicates total number of $R T-P C R$ reactions for a given subtype of $D A$ receptor.

generated DGCs $(110.4 \pm 7.4 \%, n=6)$ (Fig. $6 B$ ), although it appeared to reverse faster on washout than $\mathrm{D}_{2}$-LTD. Together, these findings suggest that preblockade of AC by SQ 22536 occluded $\mathrm{D}_{2}$ agonist-induced depression. Thus, activation of $\mathrm{D}_{2}$ like receptors in the DG appeared to decrease intracellular cAMP accumulation by inhibiting AC.

Forskolin produced an even stronger potentiation of EPSCs in 4 wpi adult-generated DGCs $(137.8 \pm 11.7 \%, n=5)$ (Fig. $6 A)$, which implies that $\mathrm{D}_{2}$-like receptors were either not expressed or not coupled to the AC/cAMP pathway in young neurons. To test the first possibility, we used a DGC-specific RT-PCR technique to analyze RNA transcript levels in individual newborn and mature DGCs. Since our qPCR data (Fig. $1 B$ ) indicated that $\mathrm{D}_{1}, \mathrm{D}_{2}$, and $D_{5}$ receptors appeared to be the major subtypes of DA receptors expressed in the DG, we focused on comparing the levels of the three subtypes in neurons born during early development $\left(\mathrm{GFP}^{-}\right)$versus those born during adulthood $\left(\mathrm{GFP}^{+}\right)$. In summary, we observed amplification of $\mathrm{D}_{1} / \mathrm{D}_{5}$ receptors from both $\mathrm{GFP}^{+}$and $\mathrm{GFP}^{-}$cells (Fig. $6 C$, Table 2). Expression of $\mathrm{D}_{2}$ receptors was found in $>5$-week-old $\mathrm{GFP}^{+}$and $\mathrm{GFP}^{-}$cells but not in 4 -week-old GFP ${ }^{+}$cells (Fisher's exact probability test, $p=0.1$ ). Due to the intrinsic low-level expression of DA receptors and limited amount of RNA obtained by this method, the success rate of detecting DA receptor mRNAs varied. Thus, we could neither conclude that $D_{2}$ receptors were absolutely absent in young DGCs nor compare the relative abundance of $\mathrm{D}_{2}$ receptors during cell maturation (5-week-old $\mathrm{GFP}^{+}$vs 8 -week-old $\mathrm{GFP}^{+}$vs $\left.\mathrm{GFP}^{-}\right)$. However, these results clearly suggest that $\mathrm{D}_{1}$-like $\left(\mathrm{D}_{1}\right.$ and $\mathrm{D}_{5}$ ) receptors were expressed in both mature (8-week-old $\mathrm{GFP}^{+}$and $\mathrm{GFP}^{-}$) and immature DGCs, whereas $\mathrm{D}_{2}$ receptors were more easily detected in mature neurons but were undetectable from 16 RT-PCRs of young cells.

To determine whether $\mathrm{D}_{1}$ - and $\mathrm{D}_{2}$-LTD involve PLC activation or $\mathrm{Ca}^{2+}$-dependent intracellular signaling processes, we then separately tested the effects of SKF 38393 and quinpirole in the presence of a PLC inhibitor, U73122 (10 $\mu \mathrm{M})$, or $\mathrm{a} \mathrm{Ca}^{2+}$ chelator, BAPTA-AM $(10 \mu \mathrm{M})$. BAPTA-AM treatment alone induced a gradual decrease of synaptic transmission, indicating a strong $\mathrm{Ca}^{2+}$ chelation. The reduction of EPSC amplitude generally reached a steady state $\sim 40$ min after drug application (supplemental Fig. S4B, available at www. jneurosci.org as supplemental material). Thus, we compared the EPSC amplitudes after DA agonist administration with those new stable baselines acquired after the slices were perfused with the drug for $>1$ h. Constant perfusion of U73122 failed to significantly block DA receptor stimulation-induced depression (Fig. 6D). Under this condition, activation by SKF 38393 of $\mathrm{D}_{1}$-like receptors in newborn neurons was still able to suppress the evoked EPSCs (SKF 38393 vs SKF $38393+$ $\mathrm{U}-73122: 71.7 \pm 5.6 \%$ vs $72.0 \pm 6.6 \%$; $p=0.98, t$ test $)$. Likewise, activation by quinpirole of $\mathrm{D}_{2}$-like receptors in mature DGCs decreased the amplitude of EPSCs to $73.0 \pm 8.0 \%(n=$ 7) in the presence of U73122. By contrast, pretreatment of brain slices with BAPTA-AM largely abolished $\mathrm{D}_{1}$-LTD in 4 wpi GFP ${ }^{+}$DGCs $(93.9 \pm 8.3 \%, n=5)$. The magnitude of $\mathrm{D}_{2}$-LTD in $\mathrm{GFP}^{-}$DGCs was also markedly reduced (quinpirole + BAPTA-AM vs quinpirole: $87.9 \pm 2.7 \%$ vs $70.7 \pm$ $5.3 \%$; $p<0.05, t$ test), even though quinpirole still caused a statistically significant reduction of evoked EPSCs in the presence of BAPTA-AM. These results indicate that $\mathrm{Ca}^{2+}$ chelation blocked or occluded the effects of DA agonists. The changes in presynaptic and/or postsynaptic intracellular $\mathrm{Ca}^{2+}$, independent of PLC activation, played an essential role in depression mediated by both families of DA receptors.

Prior studies have also reported that the actions of $D_{1} / D_{5}$ receptor agonists require NMDA receptor-mediated synaptic transmission (Smith et al., 2005), and we consistently observed NMDA receptor-mediated currents under our recording condition, albeit of small amplitudes (supplemental Fig. S5, available at www.jneurosci.org as supplemental material). We therefore investigated the dependency of $\mathrm{D}_{1} / \mathrm{D}_{2}$-LTD on NMDA receptors by applying the agonists in the presence of the competitive NMDA receptor antagonist D-AP5 $(25 \mu \mathrm{M})$. As shown in Figure $6 D$, blockade of NMDA receptor activation completely abolished the depression induced by SKF 38393 in $\mathrm{GFP}^{+}$cells (102 $\pm 8.7 \%$ of baseline). However, in $\mathrm{GFP}^{-}$neurons, the mean amplitude of evoked EPSCs measured between 30 and $40 \mathrm{~min}$ following bath application of quinpirole in the presence of D-AP5 was $75.1 \pm 4.2 \%$ of the control level $(n=9)$, which was comparable to that obtained in the absence of D-AP5. Thus, $\mathrm{D}_{1}$ like receptor-mediated depression of entorhinal inputs to newborn DGCs seemed to be dependent on synaptic activation of NMDA receptors, whereas this mechanism was not required for the $\mathrm{D}_{2}$-like receptor-mediated effect on mature neurons.

\section{Prior $\mathrm{D}_{1}$-LTD expression alters the magnitude of LTP in immature DGCs}

To examine whether activation of distinct subtypes of DA receptors accounts for the differential modulation of LTP expression in mature and newborn neurons shown in Figure 2C, we delivered TBS to DGCs of different age groups 50 min after application of $\mathrm{D}_{1}$ - or $\mathrm{D}_{2}$-like receptor agonists, when the EPSC amplitude appeared to reach a plateau after drug treatment. This induction of LTP returned the EPSC amplitude to a level not significantly different from original baseline in neurons of all three different ages ( 4 wpi: $n=8, p=0.20$; 8 wpi: $n=5, p=$ 0.49 ; mature: $n=6, p=0.92$; paired $t$ test) (Fig. $7 A-C$ ), suggesting that TBS-LTP could reverse LTD mediated by both families of DA receptors. Although SKF 38393 had no detectable influence on the strength of MPP inputs to mature DGCs (Fig. $3 A$ ), we decided to investigate whether activation of $D_{1}$ like receptors could modulate subsequent LTP induction in mature $\mathrm{GFP}^{-}$neurons. The experimental strategy was the same as that shown in Figure $7 A$, so we could compare the impact of $\mathrm{D}_{1}$ activation with that of $\mathrm{D}_{2}$ activation. In this experiment, LTP was successfully induced by TBS, and the increase in EPSC amplitude was $153.3 \pm 9.5 \%(n=7)$ after perfusion of SKF 38393 compared with $160.5 \pm 10.2 \%(n=$ 16 ) in control conditions, a difference that was not statistically significant ( $p=0.67, t$ test) (Fig, $7 C, D)$. Remarkably, the mean magnitude of LTP in developing DGCs (4 wpi GFP ${ }^{+}$) obtained after SKF 38393 exposure was significantly smaller than that obtained before drug treatment. However, there was no statistical difference in the levels of LTP between the mature DGCs (including $\mathrm{GFP}^{-}$and 8 wpi $\mathrm{GFP}^{+}$) expressing $\mathrm{D}_{2}$-LTD and the drug-naive DGCs (Fig. 7D). Together, these 

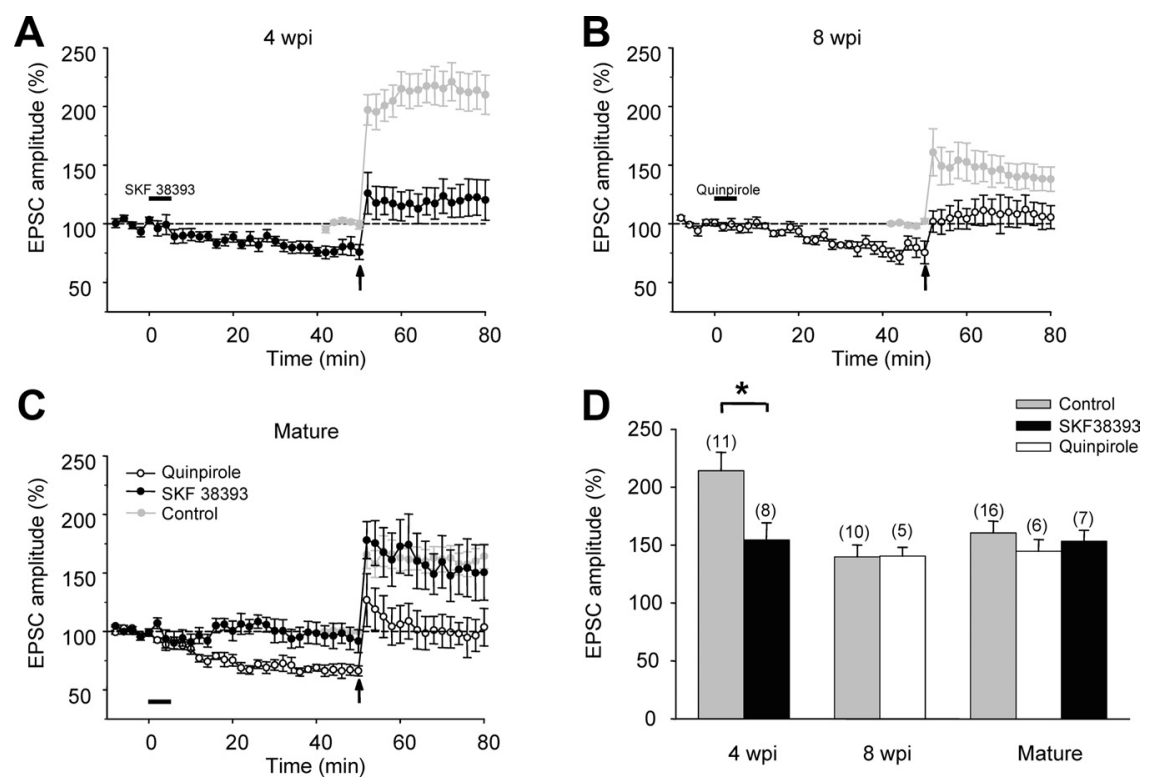

Figure 7. DA signaling through $D_{1}$-like receptors specifically regulates synaptic plasticity of immature adult-born DGCs. $A, B$, Summary of TBS-LTP recorded from GFP ${ }^{+}$DGCs at 4 wpi $(n=8)$ and 8 wpi $(n=5)$ previously treated by $D_{1}$ - or $D_{2}$-like agonists compared with LTP in control groups (gray; 4 wpi: $n=11 ; 8$ wpi: $n=10$ ). Data are presented as in Figure 2C. Arrow represents delivery of TBS protocol. C, Pretreatment of mature GFP ${ }^{-}$DGCs with SKF $38393(n=7)$ or quinpirole $(n=6)$, indicated as black bar, does not have an effect on the amplitude of subsequent TBS-LTP compared with that under control conditions $(n=16)$. Data are presented in the same manner as in $\boldsymbol{A}$. D, Summary of results from experiments in $\boldsymbol{A}-\boldsymbol{C}$. The magnitudes of LTP $20-30$ min after the end of TBS in control drug-naive DGCs (gray) and in those treated with SKF 38393 (black) or quinpirole (white) are compared. Each bar represents mean \pm SEM. ${ }^{*} p<0.05, t$ test. The number of cells examined under each condition is indicated in parentheses.

results suggest that DA specifically decreased the plasticity of newborn DGCs via $\mathrm{D}_{1}$-like receptor-mediated signaling.

\section{Discussion}

Our findings demonstrate that DA exerted distinct modulatory effects on DGCs at different developmental stages through different receptor subtypes. Selective activation of $\mathrm{D}_{1}$-like receptors led to postsynaptically expressed LTD of synaptic transmission at MPP synapses on developing adult-born neurons, which required $\mathrm{Ca}^{2+}$ influx, possibly through NMDA channels. $\mathrm{D}_{1}$-like receptor-mediated signaling also decreased the amplitude of subsequent TBS-LTP in immature neurons. In contrast, selective activation of $\mathrm{D}_{2}$-like receptors did not influence the capacity of neonate-generated DGCs to express LTP but resulted in attenuation of basal MPP inputs to them, which appeared to involve a decrease in presynaptic release. Upon maturation, newborn neurons behaved the same as those generated in neonates in response to dopaminergic stimulation.

\section{DA receptor expression in the DG}

DA receptors are found to be relatively concentrated in the CA1 region, and dopaminergic modulation of synaptic transmission within this area relates to learning and memory (Gasbarri et al., 1996; Bach et al., 1999; Lisman and Grace, 2005). In the present study, qPCR was used to determine and compare the transcription profiles of DA family receptors in microdissected DG, CA1, and $\mathrm{CA} 3$ areas of adult hippocampus and also in a separate neural structure, the striatum, which exhibits an extremely dense innervation by dopaminergic axons. Prior analysis of mRNA band intensities suggests that striatal $D_{1}$ and $D_{2}$ receptors are expressed at high levels, whereas $\mathrm{D}_{3}, \mathrm{D}_{4}$, and $\mathrm{D}_{5}$ receptor mRNAs are present at very low levels (Missale et al., 1998), which is in agreement with the $\mathrm{qPCR}$ results presented in this report. Interestingly, although DG appeared to receive much less dopaminergic innervation (Fig. 1A), the mRNA levels of $D A$ receptors in this area were comparable to those present in the striatum (Fig. $1 B$ ). Consistent with previous quantitative autoradiographic analysis showing that the molecular layer of DG contains approximately five times as many $\mathrm{D}_{1}$-like receptors as the other areas of the hippocampus (Dawson et al., 1986), DA family receptors were apparently more concentrated in the DG than in the other hippocampal subfields, suggesting a critical role for DA in regulating the function of the DG. Furthermore, the qPCR data demonstrate that $D_{1}$ and $D_{5} m R N A s$ appeared to be the most abundant among all five DA receptors in the dentate, followed by $\mathrm{D}_{2} \mathrm{mR}$ NAs. This finding is in agreement with our observation that $\mathrm{D}_{1}$-like receptors were expressed in DGCs of all ages, whereas $D_{2}$ receptors were preferentially detected in more mature cells but not found in 16 RT-PCRs from $\sim 4$-week-old neurons (Table 2). Previously, it was reported that the affinity of $\mathrm{D}_{2}$ receptors for DA is several orders of magnitude greater than that of $D_{1}$ receptors, which makes it possible that $\mathrm{D}_{2}$ receptors play a dominant role in mature DGCs even though they express $\mathrm{D}_{1}$-like receptors as well. In addition, this difference in expression might be one mechanism underlying our observation that a higher concentration of AMT was required for induction of DA-LTD in newborn cells than in mature ones (Fig. $2 B$ ).

All DA receptors are G-protein-coupled receptors (GPCRs). The expression levels of GPCRs are generally low in native tissues and therefore hard to detect, which is partially reflected by the high variability of PCR efficiency (Figs. 1B, 6C). However, one ligand-bound GPCR may activate multiple G-proteins, depending on the duration of activated GPCR, and the signal could be further amplified along downstream signal cascades. Maintenance of the signal is not only determined by the lifetime of the ligand-GPCR complex but also is affected by the amount and lifetime of the receptor-effector protein complex, deactivation of the activated receptor, and deactivation of effectors through intrinsic enzymatic activity, which might contribute to the longlasting dopaminergic modulation observed in this study.

\section{Mechanisms underlying differential $D_{1}$ versus $D_{2}$ receptor-mediated inhibition}

Our present results demonstrate that DA selectively decreased the strength of MPP synapses on developing newborn DGCs (younger than 6 weeks of cell age) and impaired their ability to express LTP through activation of $\mathrm{D}_{1}$-like receptors, whereas $\mathrm{D}_{2}$ like receptors mediated depression of MPP synapses on mature adult-generated neurons (older than 8 weeks) and on those born during early development without disturbing their capacity to express LTP. $\mathrm{D}_{1}$-LTD in new neurons appeared not to involve the $\mathrm{AC} / \mathrm{cAMP}$ signaling cascade, as inhibition of AC failed to decrease the level of depression induced by SKF 38393. However, exposure to $\mathrm{Ca}^{2+}$ chelator or NMDA channel blocker, but not 
PLC inhibitor, largely abolished the effect of SKF 38393 through either blockade or occlusion, suggesting that $\mathrm{D}_{1}$-like receptormediated LTD involves NMDA receptors and $\mathrm{Ca}^{2+}$-dependent mechanisms. In contrast, inhibition of the AC/cAMP pathway was a prerequisite for $\mathrm{D}_{2}$-LTD. Together with the finding that forskolin-induced potentiation (Fig. $6 A, B$ ) was accompanied by a decrease in PPR (data not shown), an increase in PPR associated with $\mathrm{D}_{2}$-LTD indicates that AC-mediated signaling initiated a retrograde signal from postsynaptic DGCs, which eventually resulted in reduction of neurotransmitter release from MPP terminals. $\mathrm{D}_{2}$ receptor activation has been found to trigger release of postsynaptic endocannabinoids, which act as retrograde messengers to suppress presynaptic glutamate release (Kreitzer, 2005), thereby mediating dopaminergic inhibition of excitatory transmission onto striatal medium spiny neurons (Yin and Lovinger, 2006). Whether a similar retrograde signaling mechanism accounts for $\mathrm{D}_{2}$ actions in the DG remains to be further investigated. It is noteworthy that quinpirole depressed synaptic responses of mature DGCs to a significantly lesser degree in the presence of $\mathrm{Ca}^{2+}$ chelator, but neither PLC-linked $\mathrm{Ca}^{2+}$ immobilization nor NMDA receptor-dependent $\mathrm{Ca}^{2+}$ influx was likely to contribute to this process. Given that $\mathrm{D}_{1}$-LTD appeared to have a postsynaptic locus, whereas $\mathrm{D}_{2}$-LTD might involve a presynaptic component (Figs. 3, 4), it is possible that the impact of DA on immature DGCs requires activation of NMDA receptors and a $\mathrm{Ca}^{2+}$-driven intracellular signaling event in postsynaptic neurons. In contrast, DA influences mature DGCs through a postsynaptic $\mathrm{D}_{2}$-like receptor-linked AC/cAMP pathway and a subsequent retrograde messenger that activates a $\mathrm{Ca}^{2+}$ dependent process in the presynaptic neuron and/or whose production may itself be $\mathrm{Ca}^{2+}$ dependent in the postsynaptic neuron. Additional studies will be needed to address this issue. In conclusion, although DA resulted in similar downregulation of cortical inputs to mature and newborn DGCs, the effects on the two different groups of cells appeared to occur via distinct mechanisms, which may also underlie differential modulation of their synaptic plasticity (Fig. 8).

\section{Functional implications}

A wealth of studies has been conducted on the regulatory role of DA in synaptic transmission and plasticity of CA1 pyramidal neurons (Huang and Kandel, 1995; Otmakhova and Lisman, 1996, 1999; Matthies et al., 1997; Lemon and Manahan-Vaughan, 2006); however, the functional significance of the DA system in the DG remains elusive. The global inhibition of cortical inputs by DA revealed in this study might be crucial for optimizing signal-to-noise ratio in the DG, which is particularly important for its role as a filter for incoming sensory information.

DGCs generated in the adult hippocampus receive synaptic inputs from the entorhinal cortex and local inhibitory interneurons (van Praag et al., 2002; Overstreet Wadiche et al., 2005; Laplagne et al., 2006) and form functional synapses with interneurons and CA3 pyramidal cells (Toni et al., 2008). The integration of new neurons into the existing neural circuitry endows them with the capacity to make an impact on hippocampal function, which has been suggested by a strong correlation between adult neurogenesis and performance in hippocampusdependent learning tasks (Shors et al., 2001; Saxe et al., 2006; Dupret et al., 2008; Imayoshi et al., 2008; Zhang et al., 2008; Clelland et al., 2009). However, it remains less clear whether and how adult-born DGCs at different developmental stages contribute to specific aspects of brain function. Immature granule cells in adult animals display distinct morphological and physiological

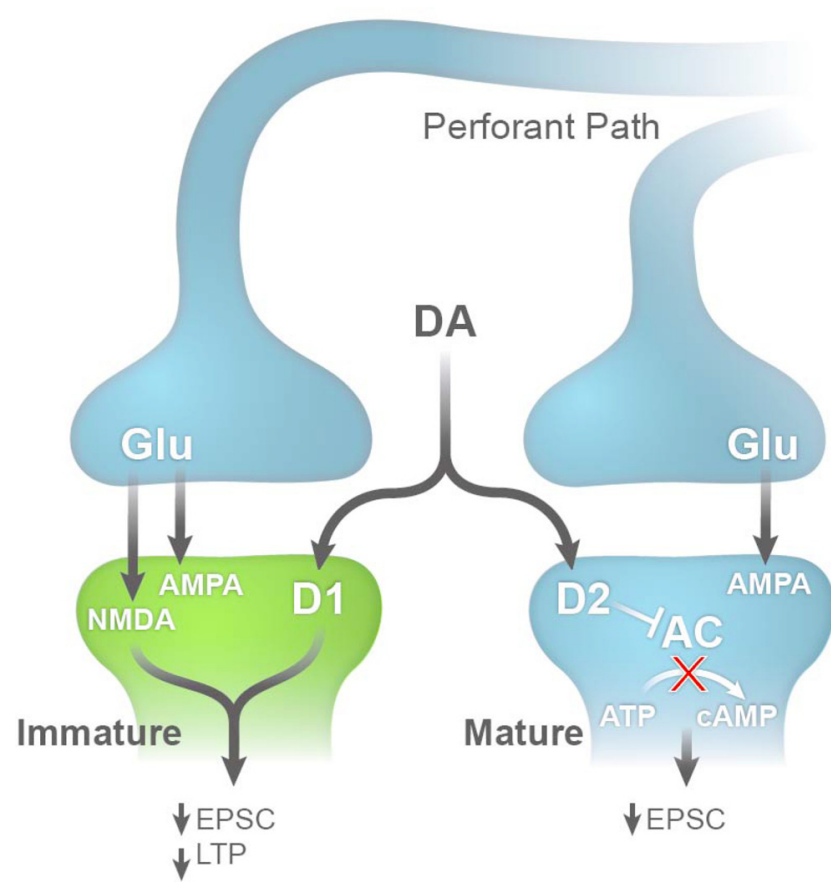

Figure 8. Schematic illustration of the mechanisms underlying DA-LTD in the adult DG. In immature adult-born DGCs (green), activation of $D_{1}$-like receptors leads to depression of MPP inputs and decreased amplitude of subsequent LTP, which involves NMDA receptor-dependent mechanisms. In mature neurons that are born during adulthood or early development (blue), activation of $D_{2}$-like receptors does not affect subsequent LTP induction but results in LTD of MPP inputs through inhibition of AC/CAMP signaling cascade. Glu, Glutamate; NMDA, NMDA receptors; AMPA, AMPA receptors.

features compared with mature ones, such as compact dendritic arbors, high excitability, and increased synaptic plasticity (Wang et al., 2000; Snyder et al., 2001; Schmidt-Hieber et al., 2004). When reaching maturity, adult-born cells become indistinguishable from newly generated ones in terms of the above properties (Laplagne et al., 2006; Zhao et al., 2006; Ge et al., 2007). One emerging view is that adult-born neurons at early stages may serve as major mediators for experience-dependent plasticity and therefore function as special units in the adult circuitry (BruelJungerman et al., 2007). Our current study extends previous findings that the physiological properties of newborn granule cells differ from those of the existing population and indicates that newborn neurons undergo a developmental switch in response to DA stimulation through an alteration of the responsible receptors from the $\mathrm{D}_{1}$ - to $\mathrm{D}_{2}$-like family. The underlying molecular mechanisms are likely to involve a developmental change in the expression level of DA receptors (Fig. 6C) and/or in the coupling efficiency of the receptors to their downstream effector proteins. Notably, the time window when LTP in new neurons is reduced by $\mathrm{D}_{1}$-like receptor-mediated signaling appears to be the same as the window when they exhibit high levels of synaptic and anatomical plasticity (Zhao et al., 2006; Ge et al., 2007). The differential dopaminergic modulation described here thus may provide an additional fine control of synaptic integration of adult-born neurons in response to experience. Given the critical role of the hippocampus-VTA loop in regulating the entry of behaviorally significant information into long-term memory (Lisman and Grace, 2005), these data have potential implications for the intriguing hypothesis that young neurons in the adult hippocampus may constitute a specific neuronal population and play unique roles in learning and memory. 


\section{References}

Abraham WC (1996) Induction of heterosynaptic and homosynaptic LTD in hippocampal sub-regions in vivo. J Physiol Paris 90:305-306.

Altman J, Das GD (1965) Autoradiographic and histological evidence of postnatal hippocampal neurogenesis in rats. J Comp Neurol 124:319-335.

Bach ME, Barad M, Son H, Zhuo M, Lu YF, Shih R, Mansuy I, Hawkins RD, Kandel ER (1999) Age-related defects in spatial memory are correlated with defects in the late phase of hippocampal long-term potentiation in vitro and are attenuated by drugs that enhance the cAMP signaling pathway. Proc Natl Acad Sci U S A 96:5280-5285.

Bear MF, Abraham WC (1996) Long-term depression in hippocampus. Annu Rev Neurosci 19:437-462.

Bruel-Jungerman E, Laroche S, Rampon C (2005) New neurons in the dentate gyrus are involved in the expression of enhanced long-term memory following environmental enrichment. Eur J Neurosci 21:513-521.

Bruel-Jungerman E, Rampon C, Laroche S (2007) Adult hippocampal neurogenesis, synaptic plasticity and memory: facts and hypotheses. Rev Neurosci 18:93-114.

Clelland CD, Choi M, Romberg C, Clemenson GD Jr, Fragniere A, Tyers P, Jessberger S, Saksida LM, Barker RA, Gage FH, Bussey TJ (2009) A functional role for adult hippocampal neurogenesis in spatial pattern separation. Science 325:210-213.

Dawson TM, Gehlert DR, McCabe RT, Barnett A, Wamsley JK (1986) D-1 dopamine receptors in the rat brain: a quantitative autoradiographic analysis. J Neurosci 6:2352-2365.

Domínguez-Escribà L, Hernández-Rabaza V, Soriano-Navarro M, Barcia JA, Romero FJ, García-Verdugo JM, Canales JJ (2006) Chronic cocaine exposure impairs progenitor proliferation but spares survival and maturation of neural precursors in adult rat dentate gyrus. Eur J Neurosci 24:586-594.

Dupret D, Revest JM, Koehl M, Ichas F, De Giorgi F, Costet P, Abrous DN, Piazza PV (2008) Spatial relational memory requires hippocampal adult neurogenesis. PLoS ONE 3:e1959.

Eriksson PS, Perfilieva E, Björk-Eriksson T, Alborn AM, Nordborg C, Peterson DA, Gage FH (1998) Neurogenesis in the adult human hippocampus. Nat Med 4:1313-1317.

Espósito MS, Piatti VC, Laplagne DA, Morgenstern NA, Ferrari CC, Pitossi FJ, Schinder AF (2005) Neuronal differentiation in the adult hippocampus recapitulates embryonic development. J Neurosci 25:10074-10086.

Gasbarri A, Sulli A, Innocenzi R, Pacitti C, Brioni JD (1996) Spatial memory impairment induced by lesion of the mesohippocampal dopaminergic system in the rat. Neuroscience 74:1037-1044.

Gasbarri A, Sulli A, Packard MG (1997) The dopaminergic mesencephalic projections to the hippocampal formation in the rat. Prog Neuropsychopharmacol Biol Psychiatry 21:1-22.

Ge S, Yang CH, Hsu KS, Ming GL, Song H (2007) A critical period for enhanced synaptic plasticity in newly generated neurons of the adult brain. Neuron 54:559-566.

Greengard P (2001) The neurobiology of slow synaptic transmission. Science 294:1024-1030.

Höglinger GU, Rizk P, Muriel MP, Duyckaerts C, Oertel WH, Caille I, Hirsch EC (2004) Dopamine depletion impairs precursor cell proliferation in Parkinson disease. Nat Neurosci 7:726-735.

Huang YY, Kandel ER (1995) D1/D5 receptor agonists induce a protein synthesis-dependent late potentiation in the CA1 region of the hippocampus. Proc Natl Acad Sci U S A 92:2446-2450.

Imayoshi I, Sakamoto M, Ohtsuka T, Takao K, Miyakawa T, Yamaguchi M, Mori K, Ikeda T, Itohara S, Kageyama R (2008) Roles of continuous neurogenesis in the structural and functional integrity of the adult forebrain. Nat Neurosci 11:1153-1161.

Jay TM (2003) Dopamine: a potential substrate for synaptic plasticity and memory mechanisms. Prog Neurobiol 69:375-390.

Kemp A, Manahan-Vaughan D (2007) Hippocampal long-term depression: master or minion in declarative memory processes? Trends Neurosci 30:111-118.

Kreitzer AC (2005) Neurotransmission: emerging roles of endocannabinoids. Curr Biol 15:R549-R551.

Laplagne DA, Espósito MS, Piatti VC, Morgenstern NA, Zhao C, van Praag H,
Gage FH, Schinder AF (2006) Functional convergence of neurons generated in the developing and adult hippocampus. PLoS Biol 4:e409.

Lemon N, Manahan-Vaughan D (2006) Dopamine $D_{1} / D_{5}$ receptors gate the acquisition of novel information through hippocampal long-term potentiation and long-term depression. J Neurosci 26:7723-7729.

Leranth C, Hajszan T (2007) Extrinsic afferent systems to the dentate gyrus. Prog Brain Res 163:63-84.

Lisman JE, Grace AA (2005) The hippocampal-VTA loop: controlling the entry of information into long-term memory. Neuron 46:703-713.

Matthies H, Becker A, Schröeder H, Kraus J, Höllt V, Krug M (1997) Dopamine D1-deficient mutant mice do not express the late phase of hippocampal long-term potentiation. Neuroreport 8:3533-3535.

Milner TA, Bacon CE (1989) Ultrastructural localization of tyrosine hydroxylase-like immunoreactivity in the rat hippocampal formation. J Comp Neurol 281:479-495.

Missale C, Nash SR, Robinson SW, Jaber M, Caron MG (1998) Dopamine receptors: from structure to function. Physiol Rev 78:189-225.

Neve KA, Seamans JK, Trantham-Davidson H (2004) Dopamine receptor signaling. J Recept Signal Transduct Res 24:165-205.

Nicoll RA, Malenka RC (1999) Expression mechanisms underlying NMDA receptor-dependent long-term potentiation. Ann N Y Acad Sci 868:515-525.

Otmakhova NA, Lisman JE (1996) $\mathrm{D}_{1} / \mathrm{D}_{5}$ dopamine receptor activation increases the magnitude of early long-term potentiation at CAl hippocampal synapses. J Neurosci 16:7478-7486.

Otmakhova NA, Lisman JE (1999) Dopamine selectively inhibits the direct cortical pathway to the CA1 hippocampal region. J Neurosci 19:1437-1445.

Overstreet Wadiche L, Bromberg DA, Bensen AL, Westbrook GL (2005) GABAergic signaling to newborn neurons in dentate gyrus. J Neurophysiol 94:4528-4532.

Park JH, Enikolopov G (2010) Transient elevation of adult hippocampal neurogenesis after dopamine depletion. Exp Neurol 222:267-276.

Saxe MD, Battaglia F, Wang JW, Malleret G, David DJ, Monckton JE, Garcia AD, Sofroniew MV, Kandel ER, Santarelli L, Hen R, Drew MR (2006) Ablation of hippocampal neurogenesis impairs contextual fear conditioning and synaptic plasticity in the dentate gyrus. Proc Natl Acad Sci U S A 103:17501-17506.

Schmidt-Hieber C, Jonas P, Bischofberger J (2004) Enhanced synaptic plasticity in newly generated granule cells of the adult hippocampus. Nature 429:184-187.

Shors TJ, Miesegaes G, Beylin A, Zhao M, Rydel T, Gould E (2001) Neurogenesis in the adult is involved in the formation of trace memories. Nature 410:372-376.

Smith WB, Starck SR, Roberts RW, Schuman EM (2005) Dopaminergic stimulation of local protein synthesis enhances surface expression of GluR1 and synaptic transmission in hippocampal neurons. Neuron 45:765-779.

Snyder JS, Kee N, Wojtowicz JM (2001) Effects of adult neurogenesis on synaptic plasticity in the rat dentate gyrus. J Neurophysiol 85:2423-2431.

Snyder JS, Hong NS, McDonald RJ, Wojtowicz JM (2005) A role for adult neurogenesis in spatial long-term memory. Neuroscience 130:843-852.

Toni N, Laplagne DA, Zhao C, Lombardi G, Ribak CE, Gage FH, Schinder AF (2008) Neurons born in the adult dentate gyrus form functional synapses with target cells. Nat Neurosci 11:901-907.

van Praag H, Schinder AF, Christie BR, Toni N, Palmer TD, Gage FH (2002) Functional neurogenesis in the adult hippocampus. Nature 415:1030-1034.

Wang S, Scott BW, Wojtowicz JM (2000) Heterogenous properties of dentate granule neurons in the adult rat. J Neurobiol 42:248-257.

Yin HH, Lovinger DM (2006) Frequency-specific and D2 receptormediated inhibition of glutamate release by retrograde endocannabinoid signaling. Proc Natl Acad Sci U S A 103:8251-8256.

Zhang CL, Zou Y, He W, Gage FH, Evans RM (2008) A role for adult TLXpositive neural stem cells in learning and behaviour. Nature 451:1004-1007.

Zhao C, Teng EM, Summers RG Jr, Ming GL, Gage FH (2006) Distinct morphological stages of dentate granule neuron maturation in the adult mouse hippocampus. J Neurosci 26:3-11.

Zhao X, Lein ES, He A, Smith SC, Aston C, Gage FH (2001) Transcriptional profiling reveals strict boundaries between hippocampal subregions. J Comp Neurol 441:187-196.

Zucker RS, Regehr WG (2002) Short-term synaptic plasticity. Annu Rev Physiol 64:355-405. 